\title{
The relationship between exercise dependence, cognitive style and personality characteristics in candidates participating in physical education and sports school special talent examination
}

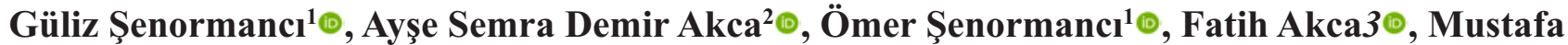 \\ Gümüşş, Fürüzan Köktürk ${ }^{5} \odot$, Rüstem Aşkın ${ }^{6} \odot$
}

${ }^{1}$ Department of Psychiatry, University of Health Sciences, Bursa Yüksek Ihtisas Training and Research Hospital, Bursa, Turkey ${ }^{2}$ Department of Family Medicine, Bülent Ecevit University School of Medicine, Zonguldak, Turkey

${ }^{3}$ Family Medicine Spesialist, Turkey Green Crescent Society, the Presidentof Zonguldak Branch, Zonguldak, Turkey

${ }^{4}$ Department of Physical Education and Sports, Bülent Ecevit University, School of Physical Education and Sports, Zonguldak, Turkey

${ }^{5}$ Department of Biostatistics, Bülent Ecevit University School of Medicine, Zonguldak, Turkey

${ }^{6}$ Department of Psychiatry, University of Health Sciences, Erenköy Mental Health and Neurology Training and Research Hospital,

Istanbul, Turkey

DOI: $10.18621 /$ eurj.445554

\begin{abstract}
Objectives: It has been suggested that there is a relationship between exercise dependence (ED), perfectionism, self-esteem and some personality characteristics.In the present study, the relations between ED and dysfunctional attitudes, self esteem and personality characteristics were evaluated.

Methods: Subjectswere 438 canditates entering special talent examination of Bülent Ecevit University School of Physical Education and Sports, Zonguldak, Turkey. Participants were evaluated with demographic data form prepared by investigators, Exercise Dependence Scale-21 (EDS-21), Dysfunctional Attitude Scale Turkish short form (DAS-R), Eysenk personality quetionnary revised form (EPQR-A) and Rosenberg Self Esteem Scale (RSES).

Results: Of the subjects participating in the study, 88 (20.1\%) were in dependent (D), 303 (69.2\%) in nondependent-symptomatic (NDS) and $47(10.7 \%)$ in non-dependent-asymptomatic (NDA) groups. There was significant difference in weekly duration of exercise hours between groups $(p=0.003)$. There was significant difference between groups in terms of DAS-R P/A (Dysfunctional Attitude Scale Turkish short formPerfectionism/achievement) scores. $(p=0.013)$ In post-hoc Dunn test carried out to determine the significance of the difference in DAS-R P/A scores between groups, no significant difference was found between D and NDS. However, there was significant difference between D and NDA and between NDAand NDS $(p<0.05)$. In multinomial regression model, it was found that when weekly duration exercise increases 1 unit in the $\mathrm{D}, 1.082$ unit increase occurs compared to NDA $(\beta=1.082, p=0.012)$.

Conclusions: It was established that in $\mathrm{D}$, perfectionist attitude was seen at a significantly higher rate than non dependent groups and duration of exercise was predictive of ED.
\end{abstract}

Keywords: Exercise dependence, perfectionism, self-esteem, personality, dysfunctional attitude

Received: July 19, 2018; Accepted: August 21, 2018; Published Online: July 25, 2019

Address for correspondence: Ömer Şenormancı, MD, Associate Professor, University of Health Sciences, Bursa Yüksek İhtisas Training and Research Hospital, Department of Psychiatry, Bursa, Turkey

E-mail: senorman_7@hotmail.com 
$\mathrm{E}$ xercise, which may be defined as regular physical activity, has many physical benefits such as treatment of diabetes, and decreasing the risk of coronary diseases; and psychological ones such as increasing self-esteem, and decreasing anxiety and depression levels $[1,2]$. It hasbeen reported that, in spite of the benefits of exercise, excessive exercise may lead to disruptive results. As in other addictions, exercise may become a compulsive behavior in time and tolerance may develop, which increases the amount of exercise, the need to exercise and withdrawal symptoms may occur in association with negative outcomes when exercise is not carried out [3]. Some investigators have termed excessive exercise as exercise dependence (ED) due to common characteristics it shares with other addicitions [4]. In the single study carried out on ED in the population, its prevalance rates were found to vary between $0.3 \%$ and $0.5 \%$ [5].

A relationship has beendemonstrated between exercise and perfectionism both in cross-sectional and longitudinal studies $[6,7]$. Self-esteem is the self perception of the individual as valuable. People constantly try not to lose their self esteem and to increase its level [8]. Adaptive perfectionism is associated with high self-esteem while maladaptive perfectionism is associated with low level self esteem [9]. Subjects with maladaptive perfectionism doubt their own actions and capacity. They frequently criticise and despise themselves [10]. Perceived physical inadequacy is associated with lack of self-acceptence and self criticism with low self esteem [11]. Gotwals et al. [12] investigated the relation between perfectionism and self esteem in sportsmen. In their study, maladaptive perfectionism was found to be associated with low self-esteem whilst no relation was found between adaptive perfectionism and self esteem [12].

Although some studies cold not findany relationship [13], it has been suggested that there is apositive correlation between ED level and extroversion, which is one of the personality dimensions, and negative correlation with neuroticism $[14,15]$. Hausenblas ve Giacobbi [16] suggested that whilst exercise is a coping strategy for concerns about being healthy and appearance,for some personality characteristics, excessive exercise may become dysfunctional in time [16]. In studies on internet addiction, which are behavioral addiction like ED, it has been reported that low self esteem and high neuroticism levels are associated with internet addiction [17]. It is known that there is a relation between perfectionism and personality characteristics such as narcissism [18]. Perfectionism is the predictor of neuroticism [19], and perfectionism and neuroticism are associated with psychiatric disorders [20].

Despite the literature, there is no consistent data on relationship between ED, perfectionism, personality characteristics, and self esteem. Contradictory results in the studies may be due to differences in the samples being studied. Risk groups need to be identified in order to prevent ED. ED may have relations with dysfunctional attitudes, self-esteem and personality characteristics. The aim of the present study was to investigate the relation between ED, and dysfunctional attitudes, self-esteem and personality characteristics in subjects attending special talent examination in physical education and sports school.

\section{METHODS}

\section{Design and Subjects}

The present cross sectional study was carried out with subjects taking special talent exam of Bülent Ecevit University School of Physical Education and Sports, Zonguldak, Turkey. All applicants from all regions of Turkey who are entering Physical Education and Sports School Special Talent Examination 2016 exam in Bülent Ecevit University were targeted for study. Because of the need for regular exercise habits to be able to pass the exam, and because the test is a specialized aptitude test on sports, the sample was chosen this way. During the six day exam period, a total of 489 male and 188 female subjects entered the exam. Five hundred thirty one candidates accepting to participate in the study and signed the consent forms. In order to prevent bias, which may stem from the use of data collection tools, scales were administered to subjects randomly without any selection. Participants filled the scales in mean 20 minutes. After scales with missing or mistaken coding were removed, statistical analysis was carried out with the data of the remaining 438 participants. The present study was approved by Ethics Committee of Bülent Ecevit University, School of Medicine Ethics Committee with approval no. 2016-90-27/07. 
Scales

Demographical data form:It was developed by the investigators and includes sociodemographic information on the participants.

Exercise depencence scale-21 (EDS-21):It is Likert type (scored between 1-6) self report scale developed with the aim of determining ED [4].Test was developed to determine exercise dependence irrespective of the type of exercise. According to scoring of test, three categories are obtained. That is, dependent subjects (D), non-dependent symptomatics (NDS) and non-dependent asymptomatics (NDA). D criteria is obtaining 5 or 6 scores from an item. Those who obtain a score of 3-4 are classified as NDS while those who obtain a score of 1-2 are classified as NDA. Turkish validity and reliability study of the scale was developed by Yeltepe and İkizler [21]. In Turkish validity-reliability study carried out with exercise dependent sample, Cronbach alpha coefficient value was found to be 0.97 [21].

Dysfunctional attitude scale Turkish short form (DAS-R): Dysfunctional Attitude Scale is Likert type self reported scale and which includes 40 items scored between 1-7 developed to evaluate dysfunctional attitudes and beliefs [22]. Turkish validity and reliability study of the short form of the scale was performed by Batmaz ve Ozdel [23]. Its Turkish form includes 13 items scored between 1-7. Turkish version of the dysfunctional attitude scale are stratified into two groups. i.e. need for approval/dependency (NFA/D) and perfectionism/achievement (P/A). In Turkish form cronbach alpha value was found to be 0.84 for NFA/D subscale, 0.75 for perfectionism/achievement and 0.84 overall [23].

Eysenck personality questionnary revised short form (EPQR-A): It is a shortened from of Eysenck personality questionnary and includes 24 items answered as yes or no. Form, has four dimensions including extroversion, neuroticism, psychoticism and lie. It evaluates personality with the dimensions of extroversion, neuroticism and psychoticism. Lie dimension aims to prevent bias during administration of form and control its validity. There are 6 items for each dimension [24]. Cronbach alpha values found in Turkish validity study were as follows: 0.78 for extroversion, 0.65 for neuroticism, 0.42 for psychoticism and 0.64 for lie [25].

Rosenberg self esteem scale (RSES): Rosenberg
Self esteem scale isa self report scale including 63 multiple choice questions. It has 12 subcategoriesin the context of the present investigation. Its first ten items wereused in order to measure self esteem. The higher the score obtained from the scale, the lower was self esteem score (0-1: was evaluated as high level of self esteem, 2-4: as moderate self esteem and 5-6: as low level of self esteem) [26]. In Turkish validity and reliability study, coefficient of validity was found to be 0.71 and reliability coefficient was found to be 0.75 using test-retest method [27].

\section{Statistical Analysis}

Statistical analyses were performed with SPSS 19.0 software (SPSS Inc., Chicago, IL, USA). Distribution of data was determined by Shapiro-Wilk test. Continuous variables were expressed as mean \pm std. deviation or median (min-max), categorical variables as frequency and percent. The Chi-square test was used to determine for difference between for categorical variables. The Kruskal-Wallis test was used to determine for differences between three groups. The Dunn test was used for post-hoc test after Kruskal-Wallis test. Mutinominal logistic regression model was constructed to account for effects of prognostic factors. Significance levels were set at $p<$ 0.05 .

\section{RESULTS}

Of the participants in the study, $88(20.1 \%)$ was in D, $303(69.2 \%)$ in NDS, and $47(10.7 \%)$ in NDA. Demographic and clinical characteristics of the groups are demonstrated in Table 1. There was significant difference in weekly duration of exercise hours between groups $(p=0.003)$ (see Table 1$)$.

Comparison of scale scores between groups is demonstrated in Table 2. There was significant difference between groups in terms of DAS-R P/A (Dysfunctional Attitude Scale Turkish short form Perfectionism/achievement) scores $(p=0.013)$ (see Table 2). In post-hoc Dunn test carried out to determine the significance of the difference in DAS$\mathrm{R} P / A$ scores between groups, no significant difference was found between D and NDS. However, there was significant difference between $\mathrm{D}$ and NDA and between NDA and NDS. 
Table 1. Comparison of demographic variables between the groups $(n=438)$.

\begin{tabular}{|c|c|c|c|c|}
\hline & Dependent & $\begin{array}{c}\text { Non-dependent } \\
\text { symptomatic }\end{array}$ & $\begin{array}{l}\text { Non-dependent } \\
\text { asymptomatic }\end{array}$ & $p$ value \\
\hline $\begin{array}{l}{ }^{+} \text {Age (yeras), } \\
\text { Median (Min-Max) }\end{array}$ & $19(18-22)$ & $19(18-35)$ & $19(18-23)$ & 0.123 \\
\hline \multicolumn{5}{|l|}{${ }^{++}$Sex } \\
\hline Female, n $(\%)$ & $31(35.2 \%)$ & $75(24.8 \%)$ & $16(34.0 \%)$ & 0.094 \\
\hline Male, n (\%) & $57(64.8 \%)$ & $228(75.2 \%)$ & $31(66.0 \%)$ & \\
\hline $\begin{array}{l}{ }^{+++} \text {BMI }\left(\mathrm{kg} / \mathrm{m}^{2}\right), \\
\text { Median (Min-Max) }\end{array}$ & $20.9 \pm 2.3$ & $21.5 \pm 2.2$ & $21.2 \pm 2.3$ & 0.702 \\
\hline $\begin{array}{l}{ }^{+} \text {Overall duration of } \\
\text { exercise (years), } \\
\text { Mediam (Min-Max) }\end{array}$ & $7(1-15)$ & $7(1-25)$ & $5.5(1-14)$ & 0.103 \\
\hline $\begin{array}{l}{ }^{+} \text {Weekly duration of } \\
\text { exercise (hours), } \\
\text { Median (Min-Max) }\end{array}$ & $12(1-35)^{\mathrm{a}}$ & $8(1-60)^{b}$ & $8(2-28)^{b}$ & 0.003 \\
\hline${ }^{++}$Use of psychiatric drugs & & & & \\
\hline Yes, n (\%) & $1(1.1 \%)$ & $5(1.7 \%)$ & $0(0.0 \%)$ & 1.000 \\
\hline No, n $(\%)$ & $87(98.9 \%)$ & $298(98.3 \%)$ & $47(100.0 \%)$ & \\
\hline \multicolumn{5}{|l|}{$\begin{array}{l}{ }^{++} \text {Previous history of } \\
\text { psychiatric disorders }\end{array}$} \\
\hline Yes, n (\%) & $0(0.0 \%)$ & $10(3.3 \%)$ & $2(4.3 \%)$ & 0.109 \\
\hline No, n $(\%)$ & $88(100.0 \%)$ & $293(96.7 \%)$ & $45(95.7 \%)$ & \\
\hline \multicolumn{5}{|l|}{${ }^{++}$Alcohol use } \\
\hline Yes, n (\%) & $3(3.4 \%)$ & $25(8.3 \%)$ & $2(4.3 \%)$ & 0.280 \\
\hline No, n (\%) & $85(96.6 \%)$ & $278(91.7 \%)$ & $45(95.7 \%)$ & \\
\hline \multicolumn{5}{|l|}{${ }^{++}$Smoking } \\
\hline Yes, n (\%) & $7(8.0 \%)$ & $51(16.8 \%)$ & $3(6.4 \%)$ & 0.030 \\
\hline No, n $(\%)$ & $81(92.0 \%)$ & $252(83.2 \%)$ & $44(93.6 \%)$ & \\
\hline \multicolumn{5}{|l|}{${ }^{++}$Substance use } \\
\hline Yes, n (\%) & $2(2.3 \%)$ & $5(1.7 \%)$ & $0(0.0 \%)$ & 0.700 \\
\hline No, n $(\%)$ & $86(97.7 \%)$ & $298(98.3 \%)$ & $47(100.0 \%)$ & \\
\hline
\end{tabular}

${ }^{+}$Kruskal-Wallis, ${ }^{++}$Chi Square, ${ }^{+++}$ANOVA(Analysis of Variance), $\mathrm{p}<0.05, \mathrm{BMI}=$ Body mass index

In order to test the predictive power of variables between groups, multinominal logistic regression analysis was carried out. Variables which meet the condition of $p<0.250$, such as age, sex, overall duration of exercise, weekly duration of exercise, previous history of psychiatric disorders, smoking status, DAS-R P/A, EPQR-A lie and RSES were entered into regression model. According to model, when weekly duration of exercise increases 1 unit in
$\mathrm{D}$, there is 1.082 unit increase compared to NDA $(\beta=1.082, p=0.012)$ (Table 3).

\section{DISCUSSION}

Although the rate of ED is low in the general community, the rates found in studies carried out with college students at similar ages are comparable to our 
Table 2. Comparison of scales between the groups $(n=438)$.

\begin{tabular}{lcccc}
\hline & Dependent & $\begin{array}{c}\text { Non-dependent } \\
\text { symptomatic }\end{array}$ & $\begin{array}{c}\text { Non-dependent } \\
\text { asymptomatic }\end{array}$ & $p$ value \\
\hline DAS-R & & & & \\
P/A, Median (Min-Max) & $20(8-48)^{\mathrm{a}}$ & $20(8-51)^{\mathrm{a}}$ & $15(8-56)^{\mathrm{b}}$ & $\mathbf{0 . 0 1 3}$ \\
NFA/D, Median (Min-Max) & $12(5-31)$ & $13.5(5-33)$ & $10(5-35)$ & 0.079 \\
$\begin{array}{l}\text { Total, Median (Min-Max) } \\
\text { EPQR-A }\end{array}$ & $32(13-74)^{\mathrm{ab}}$ & $33(13-84)^{\mathrm{a}}$ & $24(13-91)^{\mathrm{b}}$ & $\mathbf{0 . 0 1 3}$ \\
$\begin{array}{l}\text { Neuroticism, } \\
\text { Median (Min-Max) }\end{array}$ & $9(6-12)$ & $9(6-12)$ & $10(6-12)$ & 0.741 \\
$\begin{array}{l}\text { Extraversion, } \\
\text { Median (Min-Max) }\end{array}$ & $8(4-12)$ & $8(4-12)$ & $8(4-12)$ & 0.752 \\
$\begin{array}{l}\text { Psychoticism, } \\
\text { Median (Min-Max) }\end{array}$ & $7(3-12)$ & $7(3-12)$ & $8(4-10)$ & 0.999 \\
$\begin{array}{l}\text { Lie, } \\
\text { Median (Min-Max) }\end{array}$ & $10(1-12)$ & $10(1-12)$ & $9(1-12)$ & 0.164 \\
RSES, Median (Min-Max) & $1(0.25-2.75)$ & $1(0.0-4.83)$ & $1(0.0-2.75)$ & 0.193 \\
\hline
\end{tabular}

Kruskal-Wallis, $p<0.05$,

DAS-R = Dysfunctional attitude scale-revised, P/A = Perfectionism/achievement, NFA/D = Need for approval/dependency, EPQR-A = Eysenck Personality Questionnaire Revised/Abbreviated Form, RSES = Rosenberg Self-Esteem Scale

results $[28,29]$. In the present study, the rate of $\mathrm{ED}$ was two fold higher in men than in women. Data on the relative prevalence of ED in genders are conflicting. In female sex, excessive exercise occurs more commonly as a symptom of eating disorders of with the aim of losing weight. Our study was carried out with subjects entering special talent examination of Physical education and Sports school. Therefore, our sample may include intrinsically motivated subjects $[29,30]$. In the present study, weekly duration of exercise in D was significantly higher than that of NDS and NDA. Although it is not possible to give clear cutoff values for ED, Imm et al. [31] suggested that exercise at or over 5 hours a week can be considered as ED. Garman et al. [28] established, in another study carried out with college students, that the group defined as exercise dependent exercised 6 hours or more weekly. In the present study, weekly duration of exercise was found to be high in all groups. As our sample comprises subjects who wanted to enter physical education and sports department and performed exercise professionally, not as ahobby, longer exercise hours can be expected.

Perfectionism may be defined variably according to its personal and interpersonal multidimensional structure [32]. In the study by Hagan and Hausenblas [6] on university students, even when ED deriving from eating disorders was excluded, significant relation has been found between ED and perfectionism. In the study of Hall et al. [33] with a sample composed of sportsmen, it has been established that self-oriented and socially prescribed perfectionisms, which are among the dimensions of perfectionism, are associated with perfectionism. P/A which was one of the dimensions of DAS-R, used in the present study,is associated with high level of personal standarts, feeling anxious about negative evaluation of others, and evaluating faults and deficiencies as inadequacy [34]. In the present study, in $\mathrm{D}, \mathrm{DAS}-\mathrm{R} \mathrm{P} / \mathrm{A}$ dimension score was significantly higher than that in the groups without ED. This difference may be explained in different ways. Focusing on success involved with perfectionism is associated with excessively self critical and the idea of I am valuable if I am successful. Perfectionist people tend to be active physically. Anxiety about in adequacy and perception of failure may have led them to use exercise as a coping strategy [35]. Self theory 
Table 3. Summary of multinomial logistic regression analysis

\begin{tabular}{|c|c|c|c|c|c|c|}
\hline Group $^{\mathrm{a}}$ and predictor & $\begin{array}{c}\text { Wald } \\
\mathbf{x}^{2}\end{array}$ & df & B & $\begin{array}{l}\text { Odds } \\
\text { Ratio }\end{array}$ & $p$ value & $95 \%$ CI \\
\hline \multicolumn{7}{|l|}{ Dependent } \\
\hline Intercept & 0.107 & 1 & 1.005 & & 0.744 & \\
\hline Age & 1.292 & 1 & -0.75 & 0.839 & 0.256 & $0.621-1.135$ \\
\hline $\begin{array}{l}\text { Overall duration of } \\
\text { exercise (years) }\end{array}$ & 2.221 & 1 & 0.103 & 1.108 & 0.136 & $0.968-1.269$ \\
\hline $\begin{array}{l}\text { Weekly duration of } \\
\text { exercise (hours) }\end{array}$ & 6.249 & 1 & 0.079 & 1.082 & 0.012 & $1.017-1.151$ \\
\hline DAS-R P/A & 0.924 & 1 & 0.033 & 1.033 & 0.336 & $0.966-1.105$ \\
\hline DAS-R NFA/D & 0.023 & 1 & 0.007 & 1.007 & 0.880 & $0.919-1.104$ \\
\hline EPQR-A Lie & 1.738 & 1 & 0.109 & 1.116 & 0.187 & $0.948-1.313$ \\
\hline RSES & 0.77 & 1 & -0.092 & 0.912 & 0.781 & $0.477-1.746$ \\
\hline \multicolumn{7}{|l|}{ Sex } \\
\hline Male & 0.314 & 1 & -0.296 & 0.744 & 0.575 & $0.264-2.096$ \\
\hline Female & & 0 & $0^{\mathrm{b}}$ & & & \\
\hline \multicolumn{7}{|l|}{ Smoking } \\
\hline Yes & 0.205 & 1 & 0.401 & 1.493 & 0.651 & $0.264-8.452$ \\
\hline No & & 0 & $0^{\mathrm{b}}$ & & & \\
\hline \multicolumn{7}{|l|}{ Non-dependent symptomatic } \\
\hline Intercept & 0.919 & 1 & -2.460 & & 0.338 & \\
\hline Age & 0.625 & 1 & 0.098 & 1.103 & 0.429 & $0.866-1.404$ \\
\hline $\begin{array}{l}\text { Overall duration of } \\
\text { exercise (years) }\end{array}$ & 0.259 & 1 & 0.031 & 1.031 & 0.611 & $0.916-1.161$ \\
\hline $\begin{array}{l}\text { Weekly duration of } \\
\text { exercise (hours) }\end{array}$ & 0.277 & 1 & 0.015 & 1.016 & 0.599 & $0.959-1.076$ \\
\hline DAS-R P/A & 1.414 & 1 & 0.035 & 1.036 & 0.234 & $0.977-1.098$ \\
\hline DAS-R NFA/D & 0.052 & 1 & 0.009 & 1.009 & 0.820 & $0.932-1.092$ \\
\hline EPQR-A Lie & 3.704 & 1 & 0.136 & 1.146 & 0.054 & $0.998-1.316$ \\
\hline RSES & 0.028 & 1 & -0.047 & 0.954 & 0.868 & $0.547-1.663$ \\
\hline \multicolumn{7}{|l|}{ Sex } \\
\hline Male & 0.010 & 1 & 0.047 & 1.048 & 0.920 & $0.420-2.614$ \\
\hline Female & & 0 & $0^{\mathrm{b}}$ & & & \\
\hline \multicolumn{7}{|l|}{ Smoking } \\
\hline Yes & 2.007 & 1 & 1.087 & 2.965 & 0.157 & $0.659-13.337$ \\
\hline No & & 0 & $0^{\mathrm{b}}$ & & & \\
\hline
\end{tabular}

${ }^{\mathrm{a}}$ The reference category is: asemptomatik, ${ }^{\mathrm{b}}$ This parameter is set to zero because it is redundant.

DAS-R = Dysfunctional attitude scale-revised, P/A $=$ Perfectionism/achievement, NFA/D = Need for approval/dependency, EPQR-A = Eysenck Personality Questionnaire, Revised/Abbreviated Form, RSES = Rosenberg Self-Esteem Scale 
explains maladaptive perfectionism as the outcome of cognitive dissonance between real self and ideal self. In the context of theory of self, excessive exercise seems to be used as means towards the formation of perfect persona [36]. People with perfectionist attitude are known to have cognition triggering and maintaining stress and to be prone to psychiatric disorders. Increased stress levels may also have led to dependence [37]. Simply, perceived performance pressure from coaches and parents and the fear of failing to meet expectations of others may cause negative perfectionistic behavioral style. In today's fitness culture, it has been suggested that people with a perfectionist attitude can turn to exercise more for intrinsic social values [38].

In the study of Guidi et al. [39] with 79 Italian participants, it was determined that there is relation between low self esteem and ED. In the study of Bruno et al. [40] on 150 subjects from fitness clubs, low self esteem was found to be predictor of ED. In both of the above studies, scales other than self esteem scale we used were employed. In the study of Iannos and Tiggerman [41], when self-esteem, which was evaluated with a version of self esteem scale used in the present study, and some personality characteristics were compared between those who have ED and those who do not have such dependence, no significant difference was found. In the present study, there was no significant difference between groups interms of self-esteem, DAS-R NFA/D and personality dimensions. The relationship between ED, self-esteem and personality traits may vary according to the sample being studied. It has been found that people with ED associated with low self esteem and disordered eating pattern use excessive exercise to regulate their emotions and to cope with low self esteem [42]. Likewise, people with a risk of eating disorder and who exercise regularly have been found to have neurotic characteristics compared to those who are not at risk of having eating disorder [43]. These contradictory findings in the studies may be related to the motivation of people to exercise. While people motivate to exercise, to lose weight or have a better appearance, low self esteem and certain personality traits are associated with ED; this may not be related to situations when motivationis skill or career development [44]. Since the present study consisted of a sample of professionals who are interested in sports, no significant differences in self esteem and personality characteristics could be detected. Besides, Iannos veTiggerman [41] suggested that excessive exercisemay have influenced the measurement of self esteem and personality characteristics, removing the difference between groups. In order to remove the effect of excessive exercise on results, the analysis of scores obtained when the same participants quit sports or their exercise is prevented may be beneficial.

In the present study, it was found that according to regression model developed for identifying the predictors of ED, when weekly exercise duration increases 1 unit in D, compared to NDA, this increase becomes 1.082 unit. Though the length of exercise period increases risk for the development of dependence, heavy and long exercise carried out by professional sportsmen in order to be successful should be carefully distinquished from exercise [45].

\section{Limitations}

There are some limitations of the present study. DAS-R P/A dimension used in the present study does not measure perfectionism multi dimensionally. Scales based on self report were also used. Further studies including clinical interviews may be beneficial. Since the present study is a cross sectional one, it is not possible to establish cause and effect relations based upon our results. In the present study was conducted in a single center which restricts the generalization of results. It may be useful to carry out similar studies in multiple centers. It is thought that trait anxiety may be effective on ED. Trait anxiety levels were not evaluated, which may be considered another limitation of the study [46].

\section{CONCLUSION}

In the present study,in the ED group, perfectionism was significantly higher than nondependent group and the duration of exercise is predictive of ED. In cases of exercise lasting for a long duration, the risk of dependence should be kept in mind and if necessary, perfectionism should be evaluated with structured scales.

\section{Ethical standards}

The study was performed according to the 1964 
Helsinki declaration and its later amendments and was approved by the local ethics committee.

\section{Conflict of interest}

The authors disclosed no conflict of interest during the preparation or publication of this manuscript.

\section{Financing}

The authors disclosed that they did not receive any grant during conduction or writing of this study.

\section{REFERENCES}

[1] Cicero AF, D'Addato S, Santi F, Ferroni A, Borghi C. Brisighella Heart Study.Leisure-time physical activity and cardiovascular disease mortality: the Brisighella Heart Study. J Cardiovasc Med (Hagerstown) 2012;13:559-64.

[2] De Mello MT, Lemos Vde A, Antunes HK, Bittencourt L, Santos-Silva R, Tufik S. Relationship between physical activity and depression and anxiety symptoms: a population study. J Affect Disord 2013;149:241-6.

[3] Warner R, Griffiths MD. A Qualitative thematic analysis of exercise addiction: an exploratory study. Int J Net Health Addict 2006; 4:13-26.

[4] Hausenblas HA, Downs DS. Exercise dependence: a systematic review. Psychol Sport Exerc 2002;3:89-123.

[5] Mónok K, Berczik K, Urbán R, Szabó A, Griffiths MD, Farkas J, et al. Psychometric properties and concurrent validity of two exercise addiction measures: a population wide study. Psychol Sport Exerc 2012;13:739-46.

[6] Hagan AL, Hausenblas HA. The relationship between exercise dependence and perfectionism. Am J Health Stud 2003;18:133-7.

[7] Goodwin H, Haycraft E, Meyer C. Psychological risk factors for compulsive exercise: a longitudinal investigation of adolescent boys and girls. Pers Individ Dif 2014;68:83-6.

[8] Tajfel H, Turner JC. The social identity theory of intergroup behaviour. In: Worchel S, Austin WG, eds. Psychology of intergroup relations (second edition). Chicago: Nelson-Hall; 1986:7-24

[9] Ashby JS, Rice KG. Perfectionism, dysfunctional attitudes, and self-esteem: a structural equations analysis. J Couns Dev 2002;80:197-203.

[10] Blatt SJ. The destructiveness of perfectionism. Implications for the treatment of depression. Am Psychol 1995;50:1003-20.

[11] Sonstroem RJ, Morgan WP. Exercise and self-esteem: Rationale and model. Med Sci Sports Exerc 1989;21:329-37.

[12] Gotwals JK, Dunn JGH, Wayment HA. An examination of perfectionism and self-esteem in intercollegiate athletes. J Sport Behav 2002;26:17-38.

[13] Kern L. Relationship between exercise dependence and big five personality. Encephale 2010;36:212-8.

[14] Yates A, Leehey K, Shisslak CM. Running--an analogue of anorexia? N Engl J Med 1983;308:251-5.

[15] Lichtenstein MB, Christiansen E, Elklit A, Bilenberg N, Støving RK. Exercise addiction: a study of eating disorder symptoms, quality of life, personality traits and attachment styles. Psychiatry Res 2014;215:410-6.

[16] Hausenblas HA, Giacobbi PR. Relationship between exercise dependence symptoms and personality. Pers Individ Dif 2004;36:1265-73.

[17] Şenormancı Ö, Saraçlı Ö, Atasoy N, Şenormancı G, Koktürk F, Atik L. Relationship of Internet addiction with cognitive style, personality, and depression in university students. Compr Psychiatry 2014;55:1385-90.

[18] Sherrya SB, Gralnicka TM, Hewittb PL, Sherryc DL, Flettd GL. Perfectionism and narcissism: testing unique relationships and gender differences. Pers Individ Dif 2014;61-62:52-6.

[19] Flett GL, Hewitt PL, Dyck DG. Self-oriented perfectionism, neuroticism and anxiety. Pers Individ Dif 1989;10:731-5.

[20] Hewitt PL, Flett GL, Blankstein KR. Perfectionism and neuroticism in psychiatric patients and college students. Pers Individ Dif 1991;12:273-9.

[21] Yeltepe H, İkizler HC. Validation and Reliabilty Study of Exercise Dependence Scale-21 in Turkish. Bağımlılık Dergisi 2007;8:29-35.

[22] Weissman AN, Beck AT. Development and validation of the Dysfunctional Attitudes Scale. Annual meeting of the Association for the Advancement of Behavior Therapy (27-31 March 1978, Toronto), 1978. Toronto, Ontario, Canada.

[23] Batmaz S, Ozdel K. Psychometric properties of the Revised and Abbreviated form of the Turkish Version of the Dysfunctional Attitude Scale. Psychol Rep 2016;118:180-98.

[24] Francis LJ, Brown LB, Philipchalk R. The development of an abbreviated form of the Revised Eysenck Personality Questionnaire (EPQR-A): Its use among students in England, Canada, the USA and Australia. Pers Individ Dif 1992;13:443-9. [25] Karanci AN, Dirik G, Yorulmaz O. Reliability and validity studies of Turkish translation of Eysenck Personality Questionnaire Revised-Abbreviated. Turk J Psychiatry 2007; 18:254-61.

[26] Rosenberg M. Society and the adolescent self-image. Princeton: Princeton University Pres; 1965.

[27] Cuhadaroglu F. Self-esteem in the adolescent. Unpublished doctoral dissertation. Ankara: Hacettepe University; 1986.

[28] Garman JF, Hayduk DM, Crider DA, Hodel MM. Occurrence of exercise dependence in a college-aged population. J Am Coll Health 2004;52:221-8.

[29] Guidi J, Pender M, Hollon SD, Zisook S, Schwartz FH, Pedrelli $\mathrm{P}$, et al. The prevalence of compulsive eating and exercise among college students: an exploratory study. Psychiatry Res 2009; 165:154-62.

[30] Grandi S, Clementi C, Guidi J, Benassi M, Tossani E. Personality characteristics and psychological distress associated with primary exercise dependence: an exploratory study. Psychiatry Res 2011;189:270-5.

[31] Imm PS, Pruitt J. Body shape satisfaction in female exercisers and nonexercisers. Women Health 1991;17:87-96.

[32] Flett GL, Hewitt PL. Perfectionism and maladjustment: An overview of theoretical, definitional, and treatment issues. In: 
Flett GL, Hewitt LP, editors. Perfectionism: Theory, research, and treatment. Washington, DC: American Psychological Association; 2002. p.5-31.

[33] Hall HK, Hill AP, Appleton PR, Kozub SA. The mediating influence of unconditional self-acceptance and labile self-esteem on the relationship between multidimensional perfectionism and exercise dependence. Psychol Sport Exerc 2009;10:35-44.

[34] Cane DB, Olinger J, Gotlib IH, Kuiper NA. Factor structure of the dysfunctional attitude scale in a student population. J Clin Psychol 1986;42:307-9.

[35] Hall HK. Perfectionism: a hallmark quality of world class performers, or a psychological impediment to athletic development? In: Hackfort D, Tenenbaum G, editors. Essential processes for attaining peak performance. Perspectives in sport and exercise psychology Vol. 1. Oxford, UK: Meyer \& Meyer Publishers; 2006. p.178-211.

[36] Leonard NH, Harvey M. Negative perfectionism: Examining negative excessive behavior in the workplace. J Appl Soc Psychol 2008;38:585-610.

[37] DiBartolo PM, Li CY, Averett S, Skotheim S, Smith LM, Raney C, et al. The relationship of perfectionism to judgmental bias and psychopathology. Cogn Ther Res 2007;31:573-87.

[38] Macfarlane L, Owens G1, Cruz Bdel P. Identifying the features of an exercise addiction: a Delphi study. J Behav Addict 2016;5:474-84.

[39] Guidi J, Clementi C, Grandi S. Psychological distress and personality characteristics among individuals with primary exercise dependence. Riv Psichiatr 2013;48:121-9.

[40] Bruno A, Quattrone D, Scimeca G, Cicciarelli C, Romeo VM, Pandolfo G, et al. Unraveling exercise addiction: the role of narcissism and self-esteem. J Addict 2014;2014:987841.

[41] Iannos M, Tiggerman M. Personality of excessive exerciser. Pers Individ Dif 1997;22:775-8.

[42] Lichtenstein MB, Christiansen E, Elklit A, Bilenberg N, Støving RK. Exercise addiction: a study of eating disorder symptoms, quality of life, personality traits and attachment styles. Psychiatry Res 2014;215:410-6.

[43] Di Lodovico L, Dubertret C, Ameller A. Vulnerability to exercise addiction, socio-demographic, behavioral and psychological characteristics of runners at risk for eating disorders. Compr Psychiatry 2018;81:48-52.

[44] Sicilia Á, Alcaraz-Ibáñez M, Lirola MJ, Burgueño R. Influence of goal contents on exercise addiction: analysing the mediating effect of passion for exercise. J Hum Kinet 2017;59:143-53.

[45] Freimuth M, Moniz S, Kim SR. Clarifying exercise addiction: differential diagnosis, co-occurring disorders, and phases of addiction. Int $\mathrm{J}$ Environ Res Public Health 2011;8:4069-81.

[46] Coen SP, Ogles BM. Psychological characteristics of the obligatory runner: a critical examination of the anorexia analogue hypothesis. J Sport Exerc Psychol 1993;15:338-54. 